\title{
Preparation and luminescence characteristics of lanthanide phosphors crystallized in phase separated glass
}

\author{
Tetsuro JIN $\dagger$, Tomoyo OCHIISHI, Yuri SHIBUYA* and Tetsuo YAZAWA* \\ National Institute of Advanced Industrial Science and Technology (AIST), Inorganic Functional Materials Research Institute, \\ 1-8-31 Midorigaoka, Ikeda, Osaka 563-8577, Japan \\ *Graduate School of Engineering, University of Hyogo, 2167 Shosha, Himeji, Hyogo 671-2201, Japan
}

\begin{abstract}
Borosilicate glass crystallized into the borate phases $\mathrm{GdBO}_{3}: \mathrm{Tm}^{3+}$ and $\mathrm{GdF}_{3}: \mathrm{Tm}^{3+}$ was successfully prepared using the phase separation phenomenon. By optimizing its composition, the glass was 'binodal' phase separated into borate droplets inside a silica matrix. The lanthanide oxide and fluoride phosphors were restrictively created in the borate phase and an emission attributable to ${ }^{1} \mathrm{D}_{2} \rightarrow{ }^{3} \mathrm{H}_{4}$ transition of $\mathrm{Tm}^{3+}$ was observed at $458 \mathrm{~nm}$. Furthermore, the luminescent intensity of lanthanide trifluoride crystallized glass at low vibrational energy was $25 \%$ larger than that of oxide glass. Based on these results, glass phosphor appears to be a promising candidate for use as a new Gadolinium Neutron Capture Therapy material in cancerous tissue imaging.

(2017 The Ceramic Society of Japan. All rights reserved.
\end{abstract}

Key-words : Borosilicate glass, Phase separation, Luminescence, Binodal, Crystallization

[Received November 16, 2016; Accepted January 6, 2017]

\section{Introduction}

Recently, direct physical attacks on cancer cells using $\alpha$-rays emitted from an organic boron complex (Boron Neutron Capture Therapy; BNCT) have steadily progressed from the research phase to application at clinical sites. ${ }^{1)-4)}$ In this technique, the targeted ranges of tumor tissues for $\alpha$ particles and ${ }^{7} \mathrm{Li}$ nuclei, generated from ${ }^{10} \mathrm{~B}$ with a thermal neutron, are 7.3 and $4.0 \mu \mathrm{m}$, respectively, with linear energy transfer (LET) of a similar order of magnitude to the cell dimensions. ${ }^{5)}$ For this reason, organic boron complexes can be used for BNCT by introducing them into cancer cells, allowing $\alpha$ particles generated from ${ }^{10} \mathrm{~B}$ (thermal neutron cross section; $3800 \mathrm{~b}$ ) to attack the cancer cell nuclei directly. $^{2,, 6)}$ This condition greatly increases the difficulty of practical treatment of BNCT. ${ }^{157} \mathrm{Gd}$ (thermal neutron cross section; $254000 \mathrm{~b}$ ) can emit $\gamma$ rays through capture of thermal neutrons and is a promising candidate for the process of generating compounds for $\mathrm{NCT}^{7}{ }^{7}$ In addition to use in Gadolinium Neutron Capture Therapy (GdNCT), the material can serve as a contrast agent for MRI and a cancer tissue and/or cell imaging agent through its luminescent properties. On the other hand, blood vessels close to tumor tissue often have pore sizes of less than $200 \mathrm{~nm}$ and are known to be easier to pass through and to introduce more nanoparticles than in the case of the normal tissue (enhanced permeation and retention effect; EPR effect). ${ }^{8)-10)}$ As shown in Illustration I, an antibody-modified inorganic nanoparticle able to perform as a strong radiation source to penetrate cell walls and attack cell nuclei from outside the cell membrane can be a promising new candidate for drug delivery systems (DDS). Although such inorganic materials are attractive for DDS, it is difficult to modify an inorganic surface by attaching organic compounds and/or antibodies to tumor tissue. The authors have so far studied the preparation of several functional glass materials by phase separation under high temperature using borosilicate glass. ${ }^{11-17)}$ Most notably, we have succeeded in the synthesis of

\footnotetext{
Corresponding author: T. Jin; E-mail: tetsu-jin@aist.go.jp
}

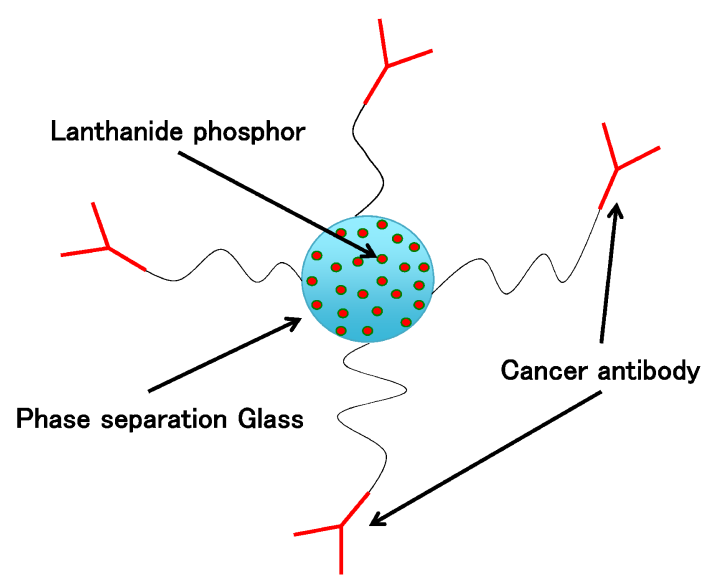

Illustration I. Application of phase separated glass with lanthanide phosphor crystals for DDS material.

red luminescent phosphors including lanthanide ions such as $\mathrm{Y}^{3+}, \mathrm{Gd}^{3+}$ and $\mathrm{Eu}^{3+}$ crystallized glass using the phase separation phenomenon. ${ }^{18)}$ Unfortunately, this glass was prepared as a 'spinodal' phase separated glass, but the borate phase (polar phase) can be easily dissolved into an acid solution with fine crystals, indicating that stable glass phosphors in air and/or aqueous (acid) solution can be synthesized as a 'binodal' phase separated glass as shown in Illustration II. Although boron and rare earth atoms possess high toxicity, the exposure to these species in the human body can be suppressed in high-durability glass, since these species can be introduced into the phase separated glass as droplets of the borate phase present in silica phase. Furthermore, the borosilicate glass host material for the functional species can be chosen by simply changing the mixing ratio of the three components in the $\mathrm{SiO}_{2}-\mathrm{B}_{2} \mathrm{O}_{3}-\mathrm{Na}_{2} \mathrm{O}$, in contrast to the case of organic hosts.

In this study, the preparation of binodal phase separated glass through incorporation of fluorescent $\mathrm{Tm}^{3+}$ and B atoms in borosilicate glass as well as the structural and luminescent properties 


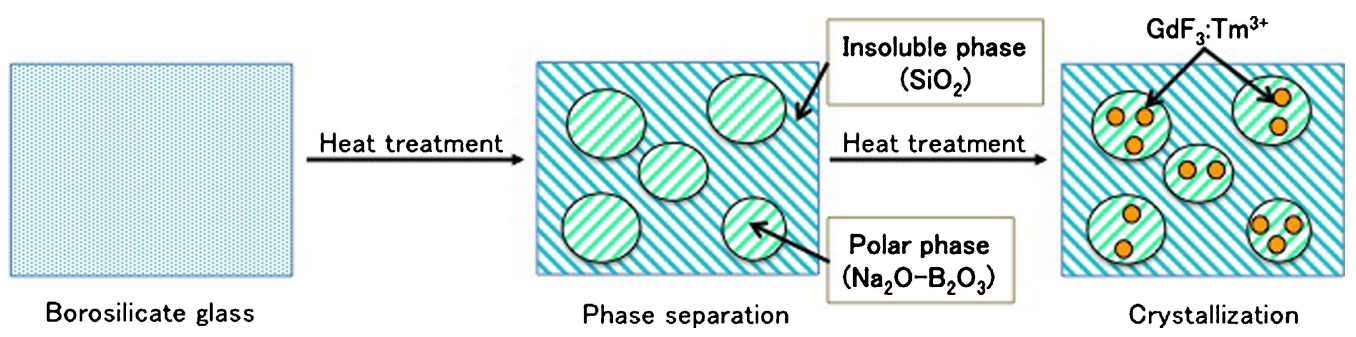

Illustration II. Conceptual image of binodal phase separation and crystallization of $\mathrm{GdF}_{3}: \mathrm{Tm}^{3+}$ in borosilicate glass.

of fine crystals in the glass were investigated.

\section{Experimental section}

For our study, $\mathrm{SiO}_{2}$ and $\mathrm{Na}_{2} \mathrm{CO}_{3}$ were purchased from Kishida Chemical Co., Ltd, $\mathrm{H}_{3} \mathrm{BO}_{3}$ from Kanto Chemical Co., Ltd and $\mathrm{TmF}_{3}, \mathrm{MgF}_{2}, \mathrm{CaF}_{2}, \mathrm{SrF}_{2}$, and $\mathrm{BaF}_{2}$ from Kojundo Chemical Laboratory Co., Ltd, and used without further purification.

The raw materials for the synthesis of the glass had chemical compositions of $65.2 \mathrm{SiO}_{2}-25.4 \mathrm{~B}_{2} \mathrm{O}_{3}-9.4 \mathrm{Na}_{2} \mathrm{O}-2.75 \mathrm{Gd}_{2} \mathrm{O}_{3}-$ $0.2 \mathrm{Tm}_{2} \mathrm{O}_{3}$ for the lanthanide borate crystallized glass and $54.6 \mathrm{SiO}_{2}-11.1 \mathrm{~B}_{2} \mathrm{O}_{3}-15.8 \mathrm{NaF}-18.5 \mathrm{Al}_{2} \mathrm{O}_{3}-5.5 \mathrm{Gd}_{2} \mathrm{O}_{3}-0.2 \mathrm{Tm}_{2} \mathrm{O}_{3}-$ $\left(\mathrm{TmF}_{3}\right)$ for the lanthanide fluoride crystallized one. The chemicals were mixed, placed into an alumina crucible and molten in an electric furnace (Motoyama Rh-2025D, SUPER-BURN) at a heating rate of $500^{\circ} \mathrm{C} / \mathrm{h}$. They were then kept at $1350^{\circ} \mathrm{C}$ for $1 \mathrm{~h}$ until the raw materials were completely molten. After the melting process, the molten glass solution was poured it into a $1.5 \times$ $2.0 \times 2.0 \mathrm{~cm}$ graphite mold. Next, the glass sample was gradually cooled from $600^{\circ} \mathrm{C}$ to room temperature in a desktop muffle furnace (DENKEN Co., Ltd, KDF P90). The resulting glass sample was cut to a thickness of $2.65 \mathrm{~mm}$ by diamond cutter (Refine Tec Co., RCA-005). Heating of untreated glass under high temperature to achieve phase separation produces an 'as-prepared' sample.

The glass was embedded in fine alumina powder (Kanto Chemical Co., alpha-type, 99\%) in an alumina crucible and heated at $800^{\circ} \mathrm{C}$ for $48 \mathrm{~h}$ in a small desktop furnace (Nitto Kagaku, NHK1170) at a heating rate of $200^{\circ} \mathrm{C} / \mathrm{h}$ for phase separation of the glass followed by crystallization of the phosphor. The glass treated under the conditions was defined as the 'crystallized' sample.

The crystalline phase was determined by an X-ray diffraction apparatus (XRD, Rigaku Ltd., Ultima IV) using a $\mathrm{Cu} \mathrm{K} \alpha 1$ line $(\lambda=1.541 \AA)$. The sample was used as the bulk and measured using a tube voltage of $40 \mathrm{kV}$, tube current of $40 \mathrm{~mA}$ and scanning speed of $2.00^{\circ} / \mathrm{min}$. The measurement angles $2 \theta$ ranged from 10 to $80^{\circ}$. Using the diffraction profile obtained by XRD measurement, the identification of crystalline in the glass was performed with 'Jade 7' X-ray analysis software.

The surface of the obtained sample was polished with waterproof SiC abrasive paper (IMT Co., Ltd, S31SR-2232000-DN), and the polished sample was measured by spectrophotometer (HITACHI, Ltd., F-2500) with a $150 \mathrm{~W}$ Xe lamp as the light source. The luminescent spectra were measured at an excitation wavelength of $355 \mathrm{~nm}$ and a measurement range 420 to $480 \mathrm{~nm}$.

Fourier Transform Infrared Spectroscopy (FT-IR) measurement was carried out using a JASCO Corporation FT/IR-480 plus by the $\mathrm{KBr}$ method under the following measurement conditions: accumulated runs: 64 ; resolution: $4 \mathrm{~cm}^{-1}$; gain: 8 ; scanning speed: $2 \mathrm{~mm} / \mathrm{sec}$, measurement range: $400-4000 \mathrm{~cm}^{-1}$.

\section{Results and discussion}

The glass was transparent when obtained but turned white after

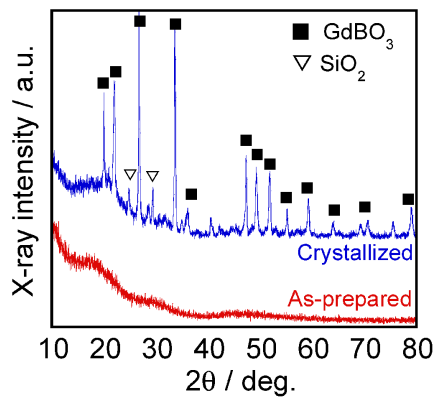

Fig. 1. XRD patterns of borate glass before and after heat treatment for phase separation.

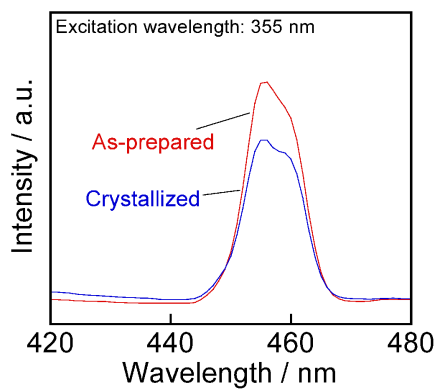

Fig. 2. Luminescence characteristics of borosilicate glass before and after heat treatment for phase separation.

heating at $800^{\circ} \mathrm{C}$ for turning phase separation. This contributed to light scattering by fine crystals in the borate phase of the phase separation glass. The XRD measurement results before and after crystallization process of the borate glass are shown in Fig. 1. Although a broad peak attributed to the amorphous phase was observed in the as-prepared sample, crystalline $\mathrm{GdBO}_{3}$ and a small $\mathrm{SiO}_{2}$ impurity peak at $800^{\circ}$ were observed.

Figure 2 shows the fluorescence spectra at an excitation wavelength of $355 \mathrm{~nm}$ before and after the crystallization process of the glass. In the spectra, a peak assigned to the ${ }^{1} \mathrm{D}_{2} \rightarrow{ }^{3} \mathrm{H}_{4}$ transition was observed at $458 \mathrm{~nm}$. Considering that the peak intensity of the crystallized sample was lower than that of asprepared sample, it is thought that the $\mathrm{Tm}^{3+}$ ion was effectively incorporated into the $\mathrm{GdBO}_{3}$ crystal. The large amount of excitation energy was transferred more easily to the non-radiative level in the lanthanide borate because $\mathrm{GdBO}_{3}$ is a material with high phonon energy, ${ }^{18)}$ and the luminescent intensity of the crystalized sample was lower than that of the as-prepared sample as a result.

The as-preprared glass containing fluoride raw materials was transparent similarly to the borosilicate glass. However, after heat treatment for phase separation the sample was devitrified and turned white due to light scattering by fine crystals in the glass. The XRD profiles of the as-preprared glass sample containing fluorides before and after phase separation treatment for crystal- 


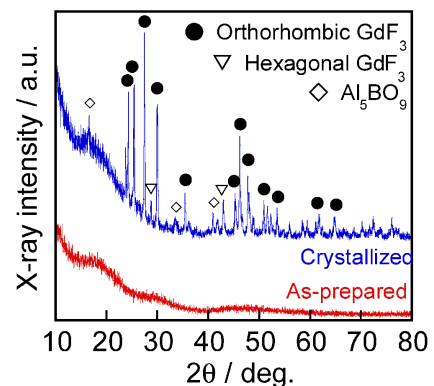

Fig. 3. XRD patterns of borosilicate glass doped lanthanide fluoride before and after heat treatment for phase separation.

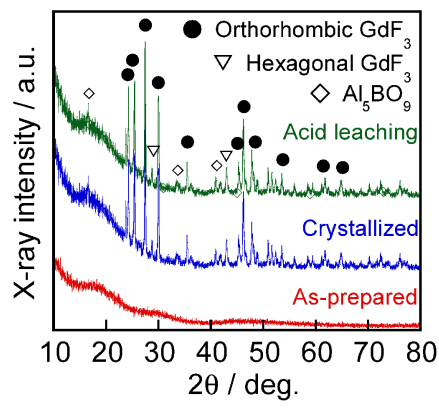

Fig. 4. XRD patterns of crystallized glass after acid treatment.

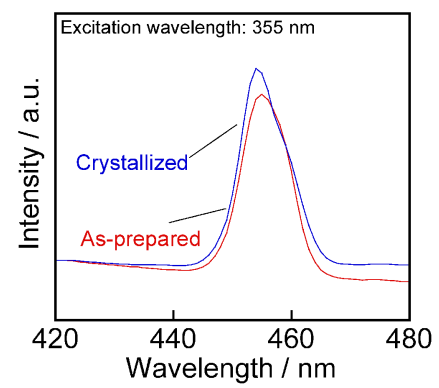

Fig. 5. Luminescent characteristics of borosilicate glass doped lanthanide fluoride before and after heat treatment for phase separation.

lization are shown in Fig. 3. Although a broad peak attributed to the as-preprared glass sample was observed, $\mathrm{GdF}_{3}$ was predominantly formed after crystallization, leading to orthorhombic dominant crystal structure and a limited number of hexagonal structures.

In order to prevent elution of boron and gadolinium from the glass due to toxicity, it is necessary to form binodal phase separation in the glass. As spherical shapes in the silica phase form when the glass separates, the borate phases are not eluted for separation, even if the glass is treated in acid solution. Therefore, in order to examine the elution of the borate phase in acid solutions, we conducted acid solution leaching treatment of the glass. Figure 4 shows the XRD results before and after acid treatment with no sign of variations in the XRD profiles. This suggested the formation of bimodal phase separation but not spinodal in the glass.

Figure 5 indicates the luminescent spectra of the glass sample excited at $355 \mathrm{~nm}$ before and after the crystallization process. An emission peak corresponding to the ${ }^{1} \mathrm{D}_{2} \rightarrow{ }^{3} \mathrm{H}_{4}$ transition can be observed at $458 \mathrm{~nm}$ similarly to the case of borosilicate glass. As for the fluoride phosphor crystallization in borosilicate glass, the luminescent intensity was slightly higher than in the case of

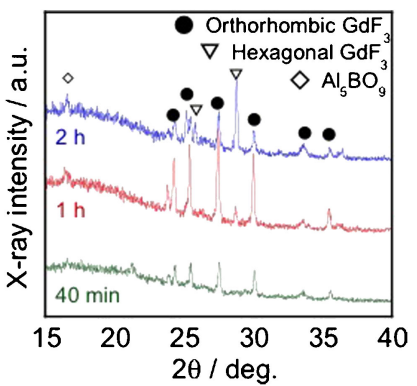

Fig. 6. XRD patterns of borosilicate glass doped with lanthanide fluoride under various melting conditions.

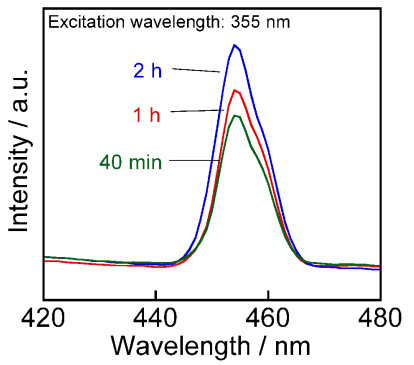

Fig. 7. Fluorescence properties of borosilicate glass doped with lanthanide fluoride at various melting conditions.

lanthanide borate phosphor.

It is well known that $\mathrm{F}^{-}$in crystal is easily volatilized when reacting with $\mathrm{O}^{2-}$ in air due to the lower melting point of the fluorine compound. Since the melting point of $\mathrm{GdF}_{3}$ is $1231^{\circ} \mathrm{C},{ }^{19}$ ) it is possible that the formation of $\mathrm{GdF}_{3}$ crystal in the phase separated glass was suppressed owing to the volatilization of fluorine during the melting process of the raw materials of the glass. First, the possibility of fluorine volatilization under various melting conditions was studied. Figure 6 shows the XRD results after crystallization under melting conditions of $40 \mathrm{~min}, 1$ and $2 \mathrm{~h}$ retention times when melting the raw materials in air. Since there are no observed oxide peaks such as $\mathrm{GdOF}$ and $\mathrm{Gd}_{2} \mathrm{O}_{3}$, the influence of fluorine volatilization is considered to be very small. In comparison to other peak intensities, the 40 min retention time peak intensity was lower overall, however the intensity of hexagonal $\mathrm{GdF}_{3}$ with increase in retention time was never theless confirmed. Orthorhombic $\mathrm{GdF}_{3}$ (space group Pnma) is thermodynamically stable at room temperature, but there are very few studies on unstable hexagonal $\mathrm{GdF}_{3} \cdot \mathrm{GdF}_{3}$ easily undergoes phase transition to the hexagonal form at higher temperatures, because the ionic radius of $\mathrm{Gd}^{3+}$ is smaller than that of $\mathrm{F}^{-}$and the repulsion between the $\mathrm{F}^{-}$ions increases.

The luminescent spectra of glass treated under the conditions described above are shown in Fig. 7. Since the luminescent intensities increase with increasing retention time, the intensity is considered to be dependent on the amount of $\mathrm{GdF}_{3}$ precipitation in the phase separation glass. In addition, the reason for the higher fluorescence intensity for the $2 \mathrm{~h}$ retention time is due to the larger amount of precipitation of the hexagonal $\mathrm{GdF}_{3}$ as compared with the orthorhombic one.

To determine the fluorine volatilization from the glass and the $\mathrm{Gd}$ atoms bonded to either the $\mathrm{O}$ atom and/or $\mathrm{F}$ atom in the glass, FT-IR measurements of the sample were made for a $1 \mathrm{~h}$ retention time as shown in Fig. 8. It is difficult to distinguish $\mathrm{Gd}_{2} \mathrm{O}_{3}$ from $\mathrm{GdF}_{3}$ because a peak is present near $450 \mathrm{~cm}^{-1}$ in both materials. Although no Gd-O peak is observed at $542 \mathrm{~cm}^{-120)}$ in the glass 


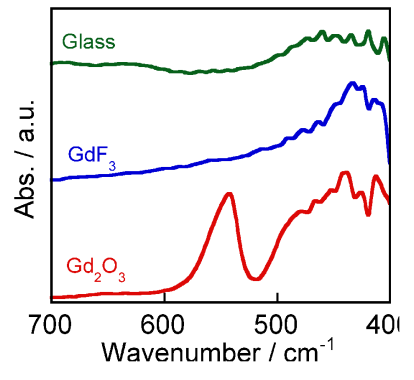

Fig. 8. FT-IR spectra of borosilicate glass doped with lanthanide fluoride with $\mathrm{GdF}_{3}$ and $\mathrm{Gd}_{2} \mathrm{O}_{3}$ as a reference sample.

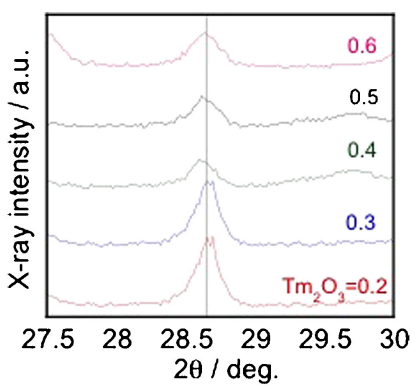

Fig. 9. Partial enlargement of XRD patterns of borosilicate glass doped with lanthanide fluoride in the $2 \theta$ range from 27.5 to 30.0 at various compositions of $\mathrm{Tm}_{2} \mathrm{O}_{3}$.

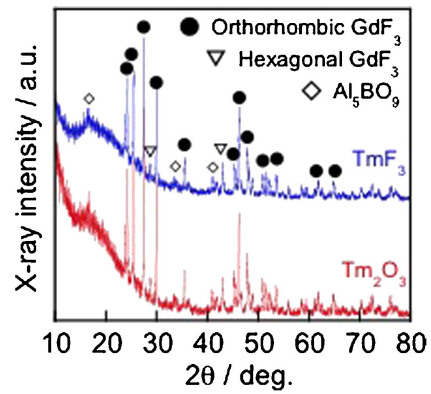

Fig. 10. XRD patterns of borosilicate glass doped with lanthanide fluoride on additional source differences between $\mathrm{Tm}_{2} \mathrm{O}_{3}$ and $\mathrm{TmF}_{3}$.

sample, one can be seen in the $\mathrm{Gd}_{2} \mathrm{O}_{3}$ reference sample. Hence the Gd in the glass is considered to be present as a fluoride. Based on these results, the volatile amount of fluorine emitted from the glass during the heating process is estimated to be very low.

XRD profiles of the glass with $\mathrm{Tm}_{2} \mathrm{O}_{3}$ compositions ranging from 0.2 to $0.6 \mathrm{~mol} \%$ at $2 \theta$ angles of 27.5 to 30 are shown in Fig. 9. By increasing the doping amount, the diffraction peak assigned to $(0,0,2)$ was shifted to a lower angle. Since the ion radiuses of $\mathrm{Tm}^{3+}$ and $\mathrm{Gd}^{3+}$ are 1.10 and $1.05 \AA$, respectively, the diffraction peak should shift to a lower angle with increases in the substituted amount of $\mathrm{Tm}^{3+}$. As the peak position of $\mathrm{GdF}_{3}$ in the XRD profile did not shift to a lower angle, however, we concluded that no $\mathrm{Tm}^{3+}$ was substituted for $\mathrm{Gd}^{3+}$ sites in the glass.

We next changed the additional source of $\mathrm{Tm}^{3+}$ in the glass from $\mathrm{Tm}_{2} \mathrm{O}_{3}$ to $\mathrm{TmF}_{3}$. The XRD results for the glass after phase separation treatment using $\mathrm{Tm}_{2} \mathrm{O}_{3}$ and $\mathrm{TmF}_{3}$ as $\mathrm{Tm}^{3+}$ sources are shown in Fig. 10. These profiles showed no difference among the additional chemicals, and the precipitation of $\mathrm{TmF}_{3}$ in the glass was confirmed in both samples. On the other hand, as seen in the results of the emission spectra in Fig. 11, the luminescent intensity of the $\mathrm{TmF}_{3}$-added glass was higher than that of the

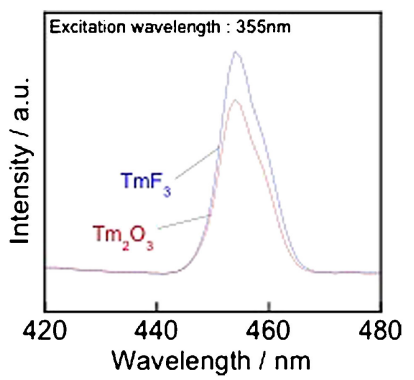

Fig. 11. Fluorescence properties of $\mathrm{Tm}_{2} \mathrm{O}_{3}$ and $\mathrm{TmF}_{3}$ sources.

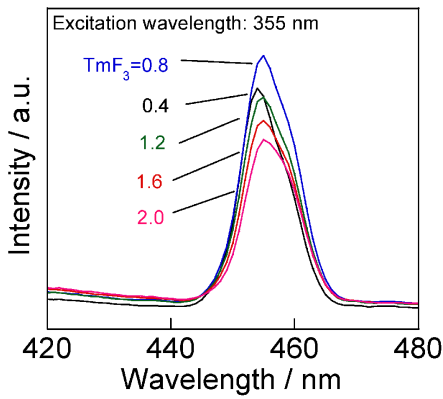

Fig. 12. Fluorescence properties of fluoride glass at various compositions of $\mathrm{TmF}_{3}$.

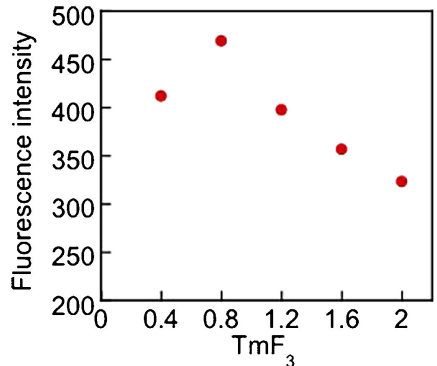

Fig. 13. Relationship between the fluorescence intensity and amount of $\mathrm{TmF}_{3}$.

$\mathrm{Tm}_{2} \mathrm{O}_{3}$-added glass. This fact reveals that $\mathrm{Tm}^{3+}$ derived from $\mathrm{TmF}_{3}$ is easier to substitute in the $\mathrm{Gd}^{3+}$ sites in $\mathrm{GdF}_{3}$. In addition, the melting points were 2425 and $1158^{\circ} \mathrm{C}$ for $\mathrm{Tm}_{2} \mathrm{O}_{3}$ and $\mathrm{TmF}_{3}$, respectively. The reason why it was easy to substitute $\mathrm{Tm}^{3+}$ in $\mathrm{TmF}_{3}$ for $\mathrm{Gd}^{3+}$ in $\mathrm{GdF}_{3}$ is that $\mathrm{TmF}_{3}$ and $\mathrm{GdF}_{3}$ have the same orthorhombic crystal structure and the melting point of $\mathrm{TmF}_{3}$ is lower than that of $\mathrm{Tm}_{2} \mathrm{O}_{3}$. To decide the optimum doping amount of $\mathrm{TmF}_{3}$, the added amount was varied from 0.4 to $2.0 \mathrm{~mol} \%$ in the phase separation glass. Figure 12 shows the fluorescence spectrum results for changes in the $\mathrm{TmF}_{3}$ composition, where the fluorescence intensity was significantly changed by the amount of doping. Figure 13 indicates the relationship between the fluorescence intensity at $458 \mathrm{~nm}$ and the amount of $\mathrm{TmF}_{3}$ amount in the glass. The maximum strength occurred at $0.8 \mathrm{~mol} \%$, decreasing in intensity with increases in the $\mathrm{TmF}_{3}$ composition. This was due to the concentration of quenching, and thus, the optimum doping amount in the glass was found to be $0.8 \mathrm{~mol} \%$.

The luminescence intensity of the fluoride crystallized glass was stronger than that of the lanthanide borate glass. As shown in Table 1, the vibrational energy of the fluoride crystallization glass was 30 to $50 \%$ smaller than that of the lanthanide borate glass. ${ }^{21}$ ) Thus, the excitation energy was prevented from diffusing into the glass phase, and we observe an increase in emission intensity. 
Table 1. Vibrational energy of glass composition

\begin{tabular}{cc}
\hline Glass composition & $v\left(\mathrm{~cm}^{-1}\right)$ \\
\hline Borate glass (B-O) & 1400 \\
Sillicate glass (Si-O) & 1200 \\
Fluoride glass (M-F) & 500 \\
\hline
\end{tabular}

\section{Conclusion}

Crystallized $\mathrm{GdBO}_{3}: \mathrm{Tm}^{3+}$ and $\mathrm{GdF}_{3}: \mathrm{Tm}^{3+}$ in glass suitable for such roles as MRI contrast agents, bio-imaging and GdNCT was successfully synthesized using the phase separation phenomena. In this study, we were able to deduce the following:

1. In glass crystallized $\mathrm{GdF}_{3}: \mathrm{Tm}^{3+}$, it was confirmed that there are two types of crystal structure; orthorhombic and hexagonal.

2. Since dissolution of crystals was not observed after acid leaching treatment, the phase separation glass was formed in the binodal phase, and it was shown that $\mathrm{GdF}_{3}$ crystals were precipitated in $\mathrm{B}_{2} \mathrm{O}_{3}$ spherical phases.

3. There were no impurity peaks such as $\mathrm{GdOF}$ and $\mathrm{Gd}_{2} \mathrm{O}_{3}$ in the glass with lanthanide fluoride XRD profiles, and there was a $\mathrm{Gd}-\mathrm{O}$ peak in FT-IR. Hence, the volatility of fluorine emitted from the phase separated glass was confirmed to be very small.

4. The luminescent intensity of the lanthanide trifluoride crystallized glass was higher than that of borate glass. From this result, the fluoride glass was found to be suitable as a material for bio-imaging and GdNCT due to the high Gd concentration in the glass.

Acknowledgment A part of this study was supported by a JSPS Grant-in-Aid for Scientific Research (B) (KAKENHI) Grant Number JP24350098.

\section{References}

1) H. Hatanaka and K. Sano, Z. Neurol., 204, 309-332 (1973).

2) Y. Mishima, M. Ichihashi, S. Hatta, C. Honda, K. Yamamura and T. Nakagawa, Pigment Cell Res., 2, 226-231 (1989).

3) Y. Sakurai and T. Kobayashi, Nucl. Instrum. Methods Phys. Res. A, 453, 569-596 (2000).

4) K. Yokoo, T. Yamada, F. Sakurai, T. Nakajima, N. Onishi and H. Izumo, "Advances in Neutron Capture Therapy, Vol. 1, Medicine and Physics", Ed. by B. Larsson, J. Crawford and R. Weinreich, Amsterdam (1997) pp. 326-354.

5) S. A. Eager, V. Giusti, M.-A. Fortin, H. Lundqvist and P. M. af Rosenschold, Radiat. Meas., 59, 233-240 (2013).

6) A. H. Soloway, H. Hatanaka and M. A. Davis, J. Med. Chem., 10, 714-717 (1967).

7) E. Fujinaka, Y. Daiko, A. Mineshige, M. Kobune, T. Yazawa, T. Jin and T. Okajima, Glass Tech.: Eur. J. Glass Sci. Technol. A, 50, 233-235 (2009).

8) H. Nehoff, N. N. Parayath, L. Domanovitch and K. Greish, Int. J. Nanomedicine, 9, 2539-2555 (2014).

9) J. Estelrich, E. Escribano, J. Queralt and M. A. Busquets, Int. J. Mol. Sci., 16, 8070-8101 (2015).

10) R. R. Sawant and V. P. Torchilin, AAPS J., 14, 303-315 (2012).

11) H. Tanaka, T. Yazawa, K. Eguchi, H. Nagasawa, N. Matsuda and T. Einishi, J. Non-crystal. Solids, 65, 301-309 (1984).

12) T. Jin, A. H. Ali and T. Yazawa, Chem. Commun. (Camb.), 99$100(2001)$

13) T. Jin, K. Kuraoka, Y. Matsumura, T. Onishi and T. Yazawa, J. Am. Ceram. Soc., 85, 2569-2571 (2002).

14) T. Jin, S. Yusa and T. Yazawa, Chem. Lett., 35, 1294-1295 (2006).

15) T. Yazawa, F. Machida, N. Kubo and T. Jin, Ceram. Int., 35, 3321-3325 (2009).

16) T. Yazawa, K. Kuraoka and W.-F. Du, J. Phys. Chem. B, 103, 9841-9845 (1999).

17) T. Yazawa, K. Kuraoka, T. Akai, N. Umesaki and W.-F. Du, J. Phys. Chem. B, 104, 2109-2116 (2000).

18) A. P. Martin, M. A. Garcia, M. J. Pascual and A. Duran, J. Non-Cryst. Solids, 384, 83-87 (2014).

19) S. V. Stankus, R. A. Khairulin and K. M. Lyapunov, J. Alloys Compd., 290, 30-33 (1991).

20) H. Guo, N. Dong, M. Yin, W. Zhang, L. Lou and S. Xia, J. Phys. Chem. B, 108, 19205-19209 (2004).

21) S. Tanabe, H. Hayashi, T. Hanada and N. Onodera, Opt. Mater., 19, 343-349 (2002). 